\title{
Reading Ability and Strategies of Students in CoAstal AREA OF BENGKULU
}

\author{
Fernandita Gusweni Jayanti, Anggun Citra Sari Dewi \\ University of Bengkulu
}

fernandita.gusweni@gmail.com, anggunsaridewi@gmail.com

\begin{abstract}
The purpose of this study is to discuss students' reading ability and the reading strategies they use when they read English texts. This study employs a descriptive-qualitative approach. The data were gained by using two instruments; a reading comprehension test and a questionnaire on reading strategy. The respondents of this research were 243 third year students from four senior high schools located in coastal area in Bengkulu city. The results of students' reading comprehension test showed that the students' reading ability is categorized as poor. This study also found that the students use reading strategies in medium frequency. It means that the students do not make use of reading strategies maximally. Furthermore, the analysis of the questionnaire also showed that the most frequently used strategies are finding the main idea of the text, guessing the meaning of difficult words and using background knowledge while reading, while the least frequently used strategies are looking at the text closely, finding specific information and interpreting graph, diagram and table. It is predicted that the students' low reading ability was influenced by the way the students use reading strategy and the sociocultural factor of the students who live in coastal area.
\end{abstract}

Keywords: reading ability, reading comprehension, reading strategy, factors

\section{INTRODUCTION}

Reading ability is crucial in today's world. The ability to read is vital in the development of the quality of human life, such as in communicating, educational process, adding knowledge, and building a career. To be more specific, reading also has an important role in someone's English learning process. To learn the language, input is the most important factor. The very famous slogan of Nuttal (1982) says that the best way to improve speech is to live in an environment that uses that language. The second way is to read extensively the various readings that use the target language. This implies that in order to use a foreign language well, language learners need inputs that use the target language. Therefore, good reading ability becomes imperative.

Unfortunately, most of the research on students' reading ability in Bengkulu also shows that most students in Bengkulu have difficulties in understanding English reading. There are several factors that make it difficult for students to understand reading texts. Most of the studies assume that this is due to the students' low English skill. However, we may not neglect the fat that many factors can affect someone's reading ability.

Good readers can understand the meaning and the way author organizes his ideas. There are many factors that can influence someone's ability in building the meaning. Jung (2009) mentions orthography, vocabulary, grammar; background knowledge and metacognitive strategies are the factors influencing L2 reading. Likewise, Koda (2007) said that vocabulary knowledge, prior knowledge, metacognitive information, and reading strategies are some variables that impact learners' reading comprehension. In the same regard, Yang (2016) points out reader's background, classroom tasks and strategies he employs are among the major factors that affect reading comprehension. Morevover, Trehearne and Doctorow (2005) claim other factors that affect learners' reading comprehension skill. These factors are learners' reading attitudes, useful teaching on comprehension methods, versatility, text form and being aware of various reading comprehension strategies. As shown above, reading strategy has a vital role in someone's reading comprehension.

Block (1986) states that reading strategies indicate how readers conceive a task, what textual cues they attend to, how they make sense of what they read, and what they do when they do not understand (quoted in Lui, 2010). In that matter, Cohen (1990 in Anderson, 2003) refers reading to those mental processes that readers consciously choose to use in accomplishing reading tasks. In short, reading strategies are deliberate, conscious active procedures or plans that a reader employs to make sense of text. There are many reading strategies employed by successful readers such as being able to organize information, use linguistic knowledge of their first language when they are learning their second language, use contextual cues, and learn how to chunk language, etc (Karbalaei, 2010). Successful language learners know how to use such reading strategies efficiently. 
Reading researchers usually divide reading strategies differently. For example, as it is quoted in Karbalaei (2010), Pressley and Afflerbach (1995) identify several key strategies that were evident in the verbal protocols they reviewed, including: (a) overview before reading; (b) look for important information and pay greater attention to it; (c) relate important points to one another; (d) activate and use prior knowledge; (e) change strategies when understanding is not good; and (f) monitor understanding and take action to correct inaccuracies in comprehension. McNamara, Ozuru, Best, and O'Reilly (2007) suggest four categories for reading strategies. The first category includes strategies to prepare to read, including setting the goals of reading. The second category regards strategies to interpret words, sentences, and ideas in texts that help reader to develop a coherent text-based level of comprehension. The third category includes strategies to go beyond the text by connecting the text content with reader's prior knowledge that help reader to develop a situation model of text. The fourth category comprises strategies to organize, restructure, and synthesize the information to facilitate global processing. General reading strategies include things such as predicting content, posing questions, recognizing text structure, integrating information, reflecting, monitoring comprehension, utilizing general knowledge, and reacting to the text (Yang, 2006).

There has been accumulated evidence that reading strategy is one of the factors affecting someone's success in reading. Earlier, Anderson (1991) reported that students who used more reading strategies on both standardized test reading and textbook reading scored higher on reading comprehension. Partially in agreement with Anderson's findings, studies in second language reading tend to show that high and low proficiency English learners use strategies differently and the variety of strategy use correlates with reading performance (Koda, 2005). In addition, Hoang (2016) found that higher-proficiency readers reported using more strategies than lower-proficiency readers, at higher frequencies.

In the same regard, Ahmadi and Pourhossein (2012) found that reading strategy has significantly affect students' reading comprehension skill. This study also explained that through using reading strategies, students can understand the major point of a paragraph, explain unfamiliar words or sentences and abridge their reading. These strategies help readers solve their difficulties when reading texts.

Another study investigating the use of specific reading strategy was conducted by Dabarera, Renandya and Zhang (2014). This study reported that students who were taught metacognitive strategies had significantly higher reading comprehension score than those on control group (taught with a traditional way; reading strategies are not explicitly taught). The result of this study supported the finding of a study by Mehrdad, et.al. (2012). This study investigated the effects of teaching cognitive and metacoginitive strategies on EFL reading comprehension across proficiency levels. This study revealed that students who were taught cognitive and metacognitive strategies had improved reading comprehension. This finding suggests that reading strategies are crucial in creating successful or less successful readers.

Unfortunately, most of the research related to students 'reading ability is more focused on the discovery and use of teaching techniques that can improve students' reading ability. Research that identifies the influence of factors that can affect students' reading ability is still very limited. Therefore, this study is intended to provide an overview of students' reading abilities as well as to explain what reading strategies students use when they try to understand English reading texts. The results of this study can help and direct teachers and policy makers to be able to prepare and arrange a reading class that can accommodate students to read by using a good reading strategy.

\section{MATERIALS AND METHOD}

This study was conducted in order to answer the following questions:

1. How is the reading ability of the students in senior high schools in coastal area of Bengkulu?

2. How is the use of reading strategies by those students?

The samples of this study were 243 students in the second year at senior high schools (SMAN) in coastal area of Bengkulu city; SMAN 8, SMAN 6, SMAN 1 and SMAN 7. The samples were chosen through purposive sampling in which the researcher deliberately chose those samples. The second year students were chosen as the samples because they have learned almost all of the text types. Two classes from each school were assigned as the samples (one social science class and one natural science class).

The schools selected to discuss in this research are schools located in the coastal area of Bengkulu City. This is based on the author's observation of reading interest and students' reading ability in coastal areas. These students are living in coastal areas and spend very little time or even never read reading 
other than school time. This is caused by a culture of reading that is rarely found in families in coastal areas. This resulted in students not being able to read them using a good reading strategy. Therefore, this study can be used as a basis for consideration to embrace students reading with a good strategy.

The data of this study was yielded by employing two instruments, a Reading Comprehension Test (RCT) and a questionnaire on reading strategies. The students were asked to complete the RCT to measure their reading ability. The test was an objective test consisting of 40 items. In this test, students were asked to read some passages and answer some following questions based on the information given in the text they have read. The passages in the test are in form of descriptive, narrative, expository, report and procedure text. According to the curriculum of English lesson in Senior High School, those types of text must have been learned by the students. From the reliability analysis, this test is considered highly reliable for its coefficient alpha 0.81 .

Students' reading ability score was calculated by using the following formula:

Score $=\frac{\text { Correct answer }}{\text { Number of items }} \times 100$

The second instrument was a questionnaire which consisted of 16 statements about the use of reading strategies. Students were asked to give response to the statements by ticking in one of the given options; N (Never), R (Rarely), S (Sometimes), O (often) and A (Always). Before the questionnaire was spread to the students, the questionnaire was examined by two experts. It was then tried out and analysed for its reliability. It was found that the reliability of the questionnaire was high with coefficient alpha 0.79 .

For data processing, response $\mathrm{N}, \mathrm{R}, \mathrm{S}, \mathrm{O}$ and $\mathrm{A}$ was scored 1, 2, 3, 4 and 5 accordingly. The frequency of the usage of each strategy was seen from the Mean score of all the responses of the respondents. Furthermore, to perceive the general use of reading strategies of the students, the following formula was used:

$\mathrm{M}=\frac{\sum \mathrm{X}}{\mathrm{N}}$

$$
\begin{aligned}
& \mathrm{M}=\text { mean } \\
& \mathrm{X}=\text { score } \\
& \mathrm{N}=\text { number of respondents }
\end{aligned}
$$

Then, the result of the mean score calculation was categorized using the following category:

Table 1 Table of Categories for Reading Strategy Frequency

\begin{tabular}{|l|l|}
\hline CATEGORY & INTERVAL \\
\hline High & $64.01-80$ \\
\hline Medium & $48.01-64$ \\
\hline Low & $32.01-48$ \\
\hline Very Low & $16-32$ \\
\hline
\end{tabular}

\section{RESULTS AND DISCUSSION}

\subsection{RESUlt OF READING COMPREHENSION TEST}

From the results of reading comprehension test, the students' reading ability was displayed in the following table: 
Table 2. Students' Score of Reading Comprehension Test

\begin{tabular}{|l|l|l|l|}
\hline CATEGORY & $\begin{array}{l}\text { SCORE } \\
\text { INTERVAL }\end{array}$ & FREQUENCY & PERCENTAGE \\
\hline Excellent & $90-100$ & 0 & $0.00 \%$ \\
\hline Very good & $80-89$ & 1 & $0.41 \%$ \\
\hline Good & $70-79$ & 13 & $5.35 \%$ \\
\hline Fair & $60-69$ & 39 & $16.05 \%$ \\
\hline Poor & $<60$ & 190 & $78.19 \%$ \\
\hline
\end{tabular}

\subsection{RESUlt OF QUESTIONNAIRE ON READING STRATEgY USE}

The data yielded from the questionnaire showed that generally, the reading strategy use of the students is categorized in medium frequency, with mean score 53.03. The result for each statement of the questionnaire is shown in Table 3.

Table 3. Table of Result of Questionnaire on Reading Strategy Use

\begin{tabular}{|l|l|l|l|}
\hline NO. & STATEMENTS & MEAN & CATEGORY \\
\hline 1. & I find information by previewing index or table of content of a book. & 3.14 & Medium \\
\hline 2. & I can find specific information in the text quickly. & 3.08 & Medium \\
\hline 3. & During reading, I guess the meaning of unfamiliar words by using cues in the text. & 3.71 & Medium \\
\hline 4. & $\begin{array}{l}\text { I try to remember any relevant experience or background knowledge related to the text } \\
\text { I read. }\end{array}$ & 3.49 & Medium \\
\hline 5. & I draw conclusion from implied statements of the author. & 3.41 & Medium \\
\hline 6. & I predict what I am going to read (what will appear in the text) next. & 3.17 & Medium \\
\hline 7. & I read closely to find details in the text. & 2.95 & Medium \\
\hline 8. & I read a long text quickly to get the main idea of the text. & 3.09 & Medium \\
\hline 9. & I use my background knowledge to comprehend a text. & 3.66 & Medium \\
\hline 10. & I can answer questions in English. & 3.14 & Medium \\
\hline 11 & I can read and interpret graph, chart, diagram and table. & 3.08 & Medium \\
\hline 12. & I can analyze long sentences. & 3.12 & Medium \\
\hline 13. & I learn the structure of the text. & 3.53 & Medium \\
\hline 14. & I can follow the movement of writer's ideas or thoughts. & 3.09 & Medium \\
\hline 15. & I can determine the title of a text. & Medium \\
\hline 16. & I can find the mind idea of a text. & Medium \\
\hline
\end{tabular}




\subsection{DisCUSSION}

Based on the result of the data analysis on reading comprehension test, it can be said that students' ability in comprehending English text was categorized as low (poor). It is shown by the fact that most of the students $(78.19 \%)$ got scores lower than 6-. Then, 16.5\% of the students got scores 60-69 (Fair). There were only 13 students (5.35\%) who had good reading ability (scores ranging from 70 to 79 ) and 1 student got an excellent score.

Regarding the analysis of the data gathered from the questionnaire, it can be seen that the students' use of reading strategy was categorized in medium frequency (53.03). It means that the students sometimes use the reading strategies and sometimes do not. This inconsistent use of reading strategies made the students incapable of using the reading strategies automatically during reading. It is predicted as one of the factors that caused the students' low reading ability.

This suspicion is supported by many previous findings that suggested positive relationship between the use of strategies and readers' reading ability or proficiency. A study by Zare (2013) found that the use of reading strategies had a strong positive correlation $(\mathrm{r}=0.92)$ with reading comprehension achievement. In his study on eighty Iranian EFL learners, Zare (2013) revealed that those language learners who have employed reading strategies more frequently got better results in reading comprehension test. In another study conducted in Malaysian ESL setting, Zare and Othman (2013) also found that the use of reading strategies had a strong positive correlation with reading comprehension ability (0.89).

Moreover, many studies also revealed the positive effects of the use of reading strategies on reading comprehension achievement. Akkakoson and Setobol (2009) conducted an experimental study on 207 undergraduate students in Thailand and revealed positive effects of strategies-based instruction on learners ${ }^{\text {ee }}$ reading proficiency. Then, in 2011, Wichadee (2011) conducted a study to investigate the effectiveness of explicit instruction of metacognitive strategies on 40 Thai EFL learners. Consistent with the previous finding, his finding indicated that metacognitive strategies instruction might have been an effective means to improve students' reading comprehension and strategy use. Later on, Aghaie and Zhang (2012) carried out a quasi-experimental design to test the effects of explicit teaching of cognitive and metacognitive reading strategies on students' reading performance and strategy transfer. After four months of strategy instruction, the experimental group achieved significantly better results than the control group.

The above findings highlight the importance of reading strategy use on someone's reading ability. Therefore, reading strategy use can be a predictor of someone's success or failure in comprehending a text.

Furthermore, the data yielded from the questionnaire also showed that among other strategies, finding main ideas $(M=3.72)$, guessing difficult words and using experience and background knowledge (3.71) were the strategies with highest frequency of use. While looking at the text closely (2.95), finding specific information quickly (3.08) and reading and interpreting graph, chart, diagram and table were the least frequent strategy they used (3.08). From this result, it can be said that the students have tried to get the big picture of the text. However, they could not comprehend the text deeper.

In relation with the result of students' reading comprehension achievement, another factor that may influence students' reading ability is the socioeconomic factor. Some studies indicate the influence of family socioeconomic conditions on the development of student literacy, especially the ability to read. Rizardo \& Tabuno, (1998) in Marquez (2008) in his study of fourth-year students 'reading comprehension at a high school in Iligan concluded that one of the factors affecting students' reading ability is parent's monthly income and parental education. Parents with sufficient monthly income are able to provide reading books for their children. It can increase students' motivation to read. Later, students who have parents with adequate educational background are shown to have better reading skills than students whose parents are uneducated or have low education. Parents who have a high education can create a supportive atmosphere and provide experiences important to the development of interest and ability to read his son.

Unfortunately, the socioeconomic condition of families on the coastline area has not supported the development of literacy, especially the development of students' learning ability. As we all know, most of the families living on the coastline belong to weak economic families. This situation does not allow students to have access to books in their home environment. In addition, the level of education of their parents also tends not to be high. They have no knowledge of the importance of developing reading skills so they cannot motivate their children to read. 
This fact supports the statement that the home environment affects children's literacy. In this matter, Wallner-Paschon (2009) pointed out the role of 'reading socialization'. Family, together with school and peer-group are important fields of socialization which in turn affect the student's motivational characteristics, such as reading attitude and reading self-concept, as well as reading achievement. In addition, a study by Martin, Mullis and Gonzalez (2004) reported that for every country participating in the Progress in International Reading Literacy Study (PIRLS) 2001, there was found a strong relationship between Grade 4 reading achievement and parents' reports of levels of engagement in literacy activities before their children started school.

\section{CONCLUSION}

The students' ability in comprehending English text is poor. The students' reading ability may be affected by several factors. One of the factors is the students' ineffective use of reading strategy as they just used reading strategy in medium frequency. However, reading strategy is essential to help students understand the text better. Therefore, an explicit instruction on strategy use is required. Teachers need to tell and train the students to deliberately use reading strategies in the reading class. Teachers should design a lesson which asks the students to actively use reading strategies.

Further, considering the socioeconomic of the students and the family, schools should take a greater role. Schools should be able to motivate the students to read and to support the development of reading habit. Schools can provide more reading sources for the students. Even more, schools can organize extensive reading program in which the students are given access to find pleasure in reading by reading non-academic books. It will increase students' reading motivation and their responsibility on their own reading progress. By being a strategic reader with high motivation reading, their reading ability will improve.

\section{REFERENCES}

Aghaie R., Zhang L. J. (2012). Effects of explicit instruction in cognitive and metacognitive reading strategies on Iranian EFL students' reading performance and strategy transfer. Instructional Science, 40 (6), 1063 -1081.

Ahmadi, M. R., \& Pourhosein Gilakjani, A. (2012). Reciprocal Teaching Strategies and Their Impacts on English Reading Comprehension. Theory and Practice in Language Studies, 2(10), 2053 2060. http://dx.doi.org/10.4304/tpls.2.10.2053-2060

Akkakoson, S., \& Setobol, B. (2009). Thai EFL students' use of strategies in reading English texts. The Journal of KMUTNB, 19 (3), 329-342.

Anderson, N. J. (1991). Individual differences in strategy use in second language reading and testing. The Modern Language Journal, 75(4), 460-472.

Anderson, N.J. (2003). Scrolling, Clicking, and Reading English: Online Reading Strategies in a Second/Foreign Language. The Reading Matrix 3(3), 1-32.

Dabarera C., Renandya W. A., Zhang L. J. (2014): The impact of metacognitive scaffolding and monitoring on reading comprehension. System: An International Journal of Educational Technology and Applied Linguistics, 42, $462-473$.

Hoang, N. (2016). The Relationship Between Reading Strategy use and Reading Proficiency of Vietnamese Students in the UK. M.A. Thesis. Northumbria University, Published by British Council ELT Master's Dissertation Awards.

Jung, J. (2009). Second language reading and the role of grammar. Working Papers in TESOL \& Applied Linguistics, 9 (2), 29-48.

Koda, K. (2005). Insights into second language reading: A cross-linguistic approach. New York: Cambridge University Press.

Koda, K. (2007). Reading Language Learning: Cross-Linguistic Constraints on Second Language Reading Development. Language Learning, 57(1), 1-44. http://dx.doi.org/10.1111/00238333.101997010-i1

Marquez, N. (2008). Factors affecting the reading comprehension of third year students Of Aurora National High School, Aurora, Zamboanga Del Sur, S.Y. 2006-2007. Published Doctoral Thesis, Philippines: National Library

Martin MO, Mullis VS \& Gonzalez E. (2004). Home environments fostering children's reading literacy: Results from the PIRLS 2001 study of reading literacy achievement in primary schools in 35 countries. Paper presented at the 1st IEA International Research Conference, Lefkosia, Cyprus. 
McNamara, D., Ozuru, Y., Best, R., \& O’Reilly, T. (2007). The 4-pronged comprehension strategy framework. In D. McNamara (Ed.), Reading comprehension strategies: Theories, interventions, and technologies (pp. 465-496). Mahwah, NJ: LEA.

Mehrdad, A. G., Ahghar, M. R., \& Ahghar, M. (2012). The effect of teaching cognitive and metacognitive strategies on EFL students' reading comprehension across proficiency levels. Procedia- Social and Behavioral Sciences, 46, 3757-3763. http://dx.doi.org/10.1016/j.sbspro.2012.06.142

Nuttall, C. (1996). Teaching Reading Skills in A Foreign Language. Great Britain: The Bath Press

Wallner-Paschon, C. (2009). Home environment, motivational characteristics, reading activities and gender: How do these factors interact and affect reading literacy of primary school students? Findings from PIRLS 2006. Paper presented at the ECER Conference, Vienna, Austria.

Wichadee, S. (2011). The effects of metacognitive strategy instruction on EFL Thai students' reading comprehension ability. Journal of College Teaching \& Learning, 8(5), 31-40.

Yang, X. (2016). Study on Factors Affecting Learning Strategies in Reading Comprehension Foreign Language School, Jiangxi Normal University, Nanchang, Jiangxi, China. Journal of Language Teaching and Research, 7( 3), 586-590.

Yang, Y. (2006). Reading strategies or comprehension monitoring strategies. Reading Psychology, 27, 313-343.

Zare, P. (2013). Exploring Reading Strategy Use and Reading Comprehension Success among EFL Learners. World Applied Sciences Journal, 22(11), 1566 - 1571.

Zare, P. and Othman, M. (2013) The Relationship between Reading Comprehension and Reading Strategy Use among Malaysian ESL Learners. International Journal of Humanities and Social Science, 3(13), $187-193$. 
